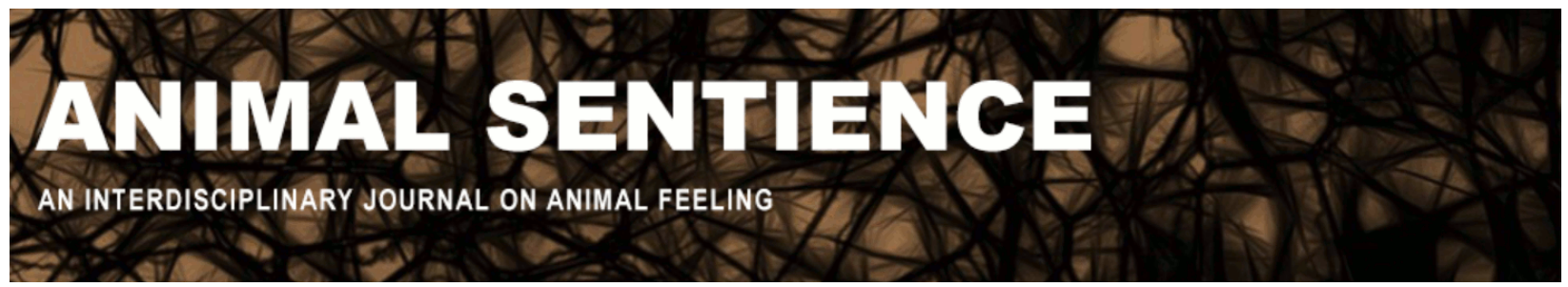

Brown, Culum (2016) Fish pain: An inconvenient truth. Animal Sentience 3(32) DOI: $10.51291 / 2377-7478.1069$

Date of submission: $2015-11-30$

Date of acceptance: 2015-12-13

(c) (i)




\title{
Fish pain: An inconvenient truth
}

Commentary II on Key on Fish Pain

\author{
Culum Brown \\ Biological Sciences \\ Macquarie University
}

\begin{abstract}
Whether fish feel pain is a hot political topic. The consequences of our denial are huge given the billions of fish that are slaughtered annually for human consumption. The economic costs of changing our commercial fishery harvest practices are also likely to be great. Key outlines a structure-function analogy of pain in humans, tries to force that template on the rest of the vertebrate kingdom, and fails. His target article has so far elicited 34 commentaries from scientific experts from a broad range of disciplines; only three of these support his position. The broad consensus from the scientific community is that fish most likely feel pain and it is time governments display courage enough to act.
\end{abstract}

Culum Brown CulumBrown@yahoo.com studies the behavioural ecology of fishes with a special interest in learning and memory. He is Associate Professor of vertebrate evolution at Macquarie University, Co-Editor of the volume Fish Cognition and Behavior, and Editor for Animal Behaviour of the Journal of Fish Biology.

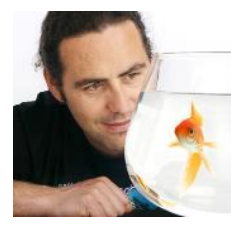
https://sites.google.com/site/culumbrown/

Key (Key 2016; Key 2016a; Key 2016b) has put forth a structure-function analogy of pain in humans and then sets out to discover how far one might take that template when applied to the rest of the vertebrate kingdom - well, fish and the odd rodent at any rate. More than 30 commenters responded to the article, and this clearly shows that this topic is still controversial. Of these, three (Rose; Hart; Diggles) support Key's position. The vast majority of commentaries, however, do not, and argue that fish most likely feel pain. Most agree that Key's argument is flawed at best, and his evidence of how pain works in humans is selective, simplistic, misleading and outdated (Damasio \& Damasio; Merker; Panksepp; Shriver). One emerging consensus, however, is that no single line of scientific evidence should over-rule any other, and many of the respondents agree that behavioural studies, such as conditioned place aversion, are an important component to understanding pain in human and nonhuman vertebrates alike.

The primary message from these commentaries is that Key's argument is fundamentally flawed from an evolutionary perspective. He argues (although later denies it) that human brain architecture is required to feel pain. The mechanistic approach centres around the role of the cortex in human pain. But as Dinets, Brown, $\mathbf{N g}$ and others point out, the human cortex has taken on a huge number of roles that once were the domain of other brain regions. To suggest that fish don't feel pain because they lack a cortex, one would also have to write-off consciousness ( $\underline{\text { Seth}}$ ) or indeed any cognitive function that occurs in the human 
cortex. One example of applying this logic would be to conclude that fish are not capable of learning either. Clearly this argument is absurd (see Brown et al. 2011; Brown 2015 for reviews). Jones, Mather, Striedter, Elwood and Edelman all point out that Key's approach also denies any possibility of convergent evolution, but surprisingly Key accepts that birds might provide an example of an independent evolution of a cortex-like structure. Haikonen, Manzotti, and Seth take it one step further and suggest that we don't even understand pain in humans yet, and it is far too early to be making judgement calls on other taxa. The role of the cortex in human pain is still debated (Stevens; Damasio \& Damasio) and is most likely

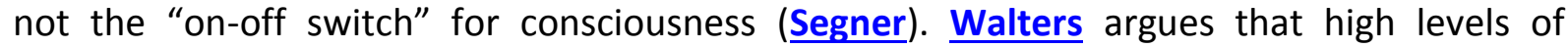
consciousness are not required for pain perception, a view which is consistent with evolution being a gradual process rather than occurring as all-or-nothing leaps and with the notion that pain is likely an ancient evolutionary trait.

Broom, Sneddon \& Leach, and Brown (2015) stated that the separation of nociception from the emotional response to it (pain) is old-fashioned and somewhat counter-productive. They argue that nociception and pain are part and parcel of the same system, and given the important nature of its function (harm avoidance), this system is likely evolutionarily ancient. It should hardly be surprising if this system is highly conserved across all vertebrates given the associated fitness advantages (Seth; Striedter; Elwood). The fact that the brain regions that are responsible vary across taxa is consistent with what we know to be the case with many other brain functions.

Diggles claims that the cheerleaders of fish pain perception (and welfare generally) intrinsically link pain with welfare. He rightly points out that other measures of welfare are available and are far less controversial. Of course the reason we are not talking about these other measures here is because they have been the foundation of fish welfare for decades (see Huntingford et al. 2006). There is no argument to be had there. The question we are addressing here is whether fish feel pain and whether we should include it in our welfare framework as we do with other vertebrates. Everyone agrees that current commercial harvesting methods are highly stressful for fish. Sadly, we currently lack the political will to do anything about it. I hope that given the known relationship between stress levels and filet quality, the aquaculture industry will move to limit pain and stress in fishes in the absence of any legislation (i.e., self-regulation driven by economics). Unfortunately, Diggles also needs a refresher course in vertebrate evolution since he wrongly states that fish are more closely related to sharks than they are to mammals and uses that as a basis for likening pain in fish to sharks rather than to mammals. It is true that "human-like" nociceptors have not been identified in elasmobranchs yet, but that is not to say that they do not exist. Science 101: Absence of evidence is not evidence of absence.

Hart rightly points out that there are issues with terminology and that humans are selfobsessed. Frankly, I think the whole consciousness debate is distracting and is not likely to be solved any time soon. We still don't really know what it is or how it is generated in humans let alone in nonhuman animals. Nevertheless, recent papers (e.g., Rey et al. 2015) certainly suggest that fish are conscious beings based on any criteria currently in use. Wadiwel suggests we should just accept that we cannot experience what other animals (or people) are feeling and that the question of pain in fish is hence one of making cautious ethical decisions under conditions of uncertainty: the weight of the evidence for and against pain in 
fish, and the weight of the consequences of a false negative (inferring fish do not feel pain when in reality they do).

The vast majority of commentaries - experts in a wide spectrum of relevant scientific and ethical specialities - accept the accumulating, multi-disciplinary evidence that it is likely that fish feel pain; moreover, even in the case of the fence-sitters (including optimistic agnostics), it is quite apparent that the precautionary principles apply, given the monumental number of fish killed each year in commercial fisheries. Indeed, Jones suggests that such a position is not only prudent, but also ethically obligatory. We should not allow conclusions drawn from scientific evidence to be tainted by the potential commercial consequences, as Key seems to recommend.

\section{References}

Broom, D.M. (2016). Fish brains and behaviour indicate capacity for feeling pain. Animal Sentience 2016.010

Brown, C. (2015). Fish intelligence, sentience and ethics. Animal Cognition, 18, 1-17

Brown, C. (2016). Comparative evolutionary approach to pain perception in fishes. Animal Sentience 2016.011

Brown, C. Krause, J. \& Laland, K. (2011). Fish Cognition and Behavior (2nd Edition). Oxford: Wiley-Blackwell.

Damasio, A. \& Damasio, H. (2016). Pain and other feelings in humans and animals. Animal Sentience 2016.059

Diggles, B.K. (2016). Fish pain: Would it change current best practice in the real world? Animal Sentience 2016.061

Dinets, V. (2016). No cortex no cry. Animal Sentience 2016.013

Edelman, D.B. (2016). Leaving the door open for fish pain: evolutionary convergence and the utility of 'just-so stories.' Animal Sentience 2016.062

Elwood, R.W. (2016). A single strand of argument with unfounded conclusion. Animal Sentience 2016.026

Haikonen, P.O. (2016). On the sentience of fish. Animal Sentience 2016.014

Hart, P.J.B. (2016). Fighting forms of expression. Animal Sentience 2016.015

Huntingford, F. A., Adams, C., Braithwaite, V. A., Kadri, S., Pottinger, T. G., Sandøe, P. \& Turnbull, J. F. (2006). Current issues in fish welfare. Journal of Fish Biology, 68, 332-372. 
Jones, R.C. (2016). Fish sentience and the precautionary principle. Animal Sentience 2016.016

Key, B. (2016). Why fish do not feel pain. Animal Sentience 2016.003

Key, B. (2016a). Going beyond just-so stories. Animal Sentience 2016.022

Key, B. (2016b). Falsifying the null hypothesis that "fish do not feel pain." Animal Sentience 2016.039

Manzotti, R. (2016). No evidence that pain is painful neural process. Animal Sentience 2016.017

Mather, J.A. (2016). A wider view of the pain problem from an invertebrate perspective. Animal Sentience 2016.018

Merker, B. (2016). Drawing the line on pain. Animal Sentience 2016.030

Ng, Y.-K. (2016). Could fish feel pain? A case for a wider, multi-faceted perspective. Animal Sentience 2016.019

Panksepp, J. (2016). Brain processes for "good" and "bad" feelings: how far back in evolution? Animal Sentience 2016.031

Rey, S., Huntingford, F.A., Boltaña, S., Vargas, S., Knowles, T.G. \& Mackenzie, S. (2015). Fish can show emotional fever: stress-induced hyperthermia in zebrafish. Proceedings of the Royal Society of London B: Biological Sciences, 282(1819).

Rose, J. D. (2016). Weighing the evidence. Animal Sentience 2016.032.

Segner, H. (2016). Why babies do not feel pain, or: how structure-derived functional intepretations can go wrong. Animal Sentience 2016.033

Seth, A.K. (2016). Why fish pain cannot and should not be ruled out. Animal Sentience 2016.020

Shriver, A. (2016). Cortex necessary for pain - not in the sense that it matters. Animal Sentience 2016.034

Sneddon, L.U. \& Leach, M.C. (2016). Anthropomorphic denial of fish pain. Animal Sentience 2016.035

Stevens, E.D. (2016). Why is fish "feeling" pain controversial? Animal Sentience 2016.036

Striedter, G. (2016). Lack of neocortex does not imply fish cannot feel pain. Animal Sentience 2016.021 
Wadiwel, D. (2016). Fish and pain: the politics of doubt. Animal Sentience 2016.038

Walters, E.T. (2016). Pain-capable neural substrates may be widely available in the animal kingdom. Animal Sentience 2016.063 